\title{
Endothelin receptor antagonist attenuates oxidative stress in a neonatal sepsis piglet model
}

Tatenobu Goto', Mohamed Hamed Hussein 1,2, Shin Kato', Ghada Abdel-Hamid Daoud ${ }^{3}$, Takenori Kato', Takahiro Sugiura', Hiroki Kakita', Masanori Nobata', Michi Kamei', Haruo Mizuno', Masaki Imai' ${ }^{4}$, Tetsuya Ito', Ineko Kato 1,5, Satoshi Suzuki', Noriko Okada ${ }^{4}$, Hajime Togari' and Hidechika Okada ${ }^{4,6}$

BACKGROUND: Oxidative stress (oxidant-antioxidant imbalance) plays an important role in the pathophysiology of neonatal sepsis. This study evaluated whether an antisense peptide endothelin receptor antagonist, ETR-P1/fl, could attenuate oxidative stress in a neonatal sepsis model.

METHODS: A total of 18 3-d-old piglets were anesthetized and mechanically ventilated. Six piglets received cecal ligation and perforation (CLP group) for induction of sepsis. Six piglets also received continuous infusion $(0.05 \mathrm{mg} / \mathrm{kg} / \mathrm{h})$ of ETR-P1/fl 30 min after CLP (ETR-P1/fl group). Six piglets received a sham operation. Serum total hydroperoxide $(\mathrm{TH})$, biological antioxidant potentials (BAPs), oxidative stress index (OSI, calculated as TH/BAP), interleukin (IL)-6, serum glutamic oxaloacetic transaminase (GOT), and creatinine were measured before CLP and at 1,3 , and $6 \mathrm{~h}$ after CLP.

RESULTS: CLP evoked a state of shock resulting in elevated TH, OSI, and IL-6 levels. ETR-P1/fl administration after CLP resulted in lower serum TH at 1 and $3 \mathrm{~h}$ after CLP, OSI at 1 and $3 \mathrm{~h}$ after CLP, IL-6 at 1 and $3 \mathrm{~h}$ after CLP, and GOT at 3 and $6 \mathrm{~h}$ after CLP as compared with the CLP group.

CONCLUSION: ETR-P1/fl treatment significantly attenuated the elevation of serum oxidative stress markers (TH and OSI), IL-6, and GOT in a progressive neonatal sepsis CLP model.

Ninas eonates, particularly low-birth-weight preterm infants, have a higher prevalence of bacterial sepsis and have greater morbidity and mortality from sepsis as compared with other infants and children despite advances in neonatal care. New approaches to neonatal sepsis are needed.

The pathophysiology of sepsis involves the endothelin system (1-3). The endothelins are a family of 21 amino-acid peptides with powerful vasoconstrictive properties first described in 1988 (4). They are derived mainly from the endothelium, which is a potent mediator of the cardiovascular system. At least three different endothelin receptors are known: the endothelin A (ETA), ETB1, and ETB2 receptors. ETA and ETB2 receptors are mainly located on vascular smooth muscle, where they mediate contraction, whereas ETB1 receptors are located on both vascular smooth muscle and the endothelium (5), where they mediate vasodilatation by the release of nitric oxide and prostacyclin (6). The production of excessive amounts of cytokines in response to an endotoxin is known to stimulate the production of ET- 1 from the endothelium (1). There is substantial evidence that ET-1 is elevated in neonates and infants with pulmonary hypertension and that it can serve as a marker of sepsis severity $(2,3)$.

A promising candidate cytokine for the diagnosis of neonatal septicemia is interleukin (IL)-6 (7), which acts as a marker of the activation status of the cytokine network and reflects the influence of several other cytokines (8). Furthermore, higher concentrations portend a poor outcome (9).

Nevertheless, newborns and particularly preterm infants are at high risk for oxidative stress, which in turn occurs when the production of reactive oxygen species (ROS) overrides the antioxidant capability; such infants are then susceptible to oxidative injury (10). This study demonstrates the effects of an endothelin receptor antagonist against serum ROS and antioxidants in a neonatal sepsis model.

Total hydroperoxide (TH) levels can serve as a measure of whole oxidative damage, given that they are affected by lipids, DNA, proteins, amino acids, and enzymes. Consequently, TH levels provide information on multiple mechanisms in the ill neonate (11). Biological antioxidant potentials (BAPs), in contrast, are used to evaluate the overall antioxidative level. Serum BAP levels provide a reliable measurement of the antioxidants that counteract the oxidant agents, which have been implicated in certain physiological and biological conditions (12).

ETR-P1/fl is the first antisense homology box-derived peptide (13) that functions as an ETA receptor antagonist in vitro (14). It also attenuates inflammatory responses during sepsis (15). We have previously suggested that ETR-P1/fl could have a suppressive effect on the release of inflammatory cytokines, including tumor necrosis factor- $\alpha$ and the highly mobile group-1 box protein, and could prolong survival time (16).

We hypothesized that blockage of the endothelin response during endotoxemia will have a beneficial effect on neonatal oxidative stress.

'Department of Pediatrics and Neonatology, Nagoya City University Graduate School of Medical Sciences, Nagoya, Japan; ${ }^{2}$ Department of Medical Research, EgyBlood, Vacsera, Giza, Egypt; ${ }^{3}$ Department of Obstetrics and Gynecology, EgyBlood, Vacsera, Giza, Egypt; ${ }^{4}$ Department of Immunology, Nagoya City University Graduate School of Medical Sciences, Nagoya, Japan; ${ }^{5}$ Department of Neonatology, Center of Maternal, Fetal and Neonatal Medicine, Saitama Medical Center, Saitama Medical University, Saitama, Japan; ${ }^{6}$ Department of Immunology, Choju Medical Institute, Fukushimura Hospital, Toyohashi, Japan. Correspondence: Mohamed Hamed Hussein (drmhamed@yahoo.com) 


\section{RESULTS}

\section{Animal Profile}

There was no significant difference among the weights of the cecal ligation and perforation (CLP), sham, and ETR-P1/fl groups $(1,646 \pm 88 \mathrm{~g}$ vs. $1,718 \pm 50 \mathrm{~g}$ vs. $1,850 \pm 106 \mathrm{~g}$, respectively).

\section{Serum TH Ratios}

Serum TH levels at each time point were compared with those measured before CLP in the same group and identified as $\triangle \mathrm{TH}$. In the CLP group, serum $\triangle \mathrm{TH}$ levels increased significantly after CLP, peaking at $1 \mathrm{~h}$ at a mean value significantly higher than those in the sham and the ETR-P1/fl groups $(1.26 \pm 0.11$ vs. $0.90 \pm 0.10$ vs. $0.84 \pm 0.13$ at $1 \mathrm{~h}, P<$ 0.05 ; Figure 1a). At $3 \mathrm{~h}$, serum $\Delta \mathrm{TH}$ levels remained higher in the CLP group than in the ETR-P1/fl group $(1.15 \pm 0.11$ vs. $0.913 \pm 0.06, P<0.05$; Figure 1a), while the levels in the ETR-P1/fl group had decreased to values similar to those in the sham group.

Serum $\Delta T H$ levels were lower in the ETR-P1/fl group than in the sham group throughout the study (Figure 1a).

\section{Serum BAPs}

The serum BAP values at each time sample were compared with those measured before CLP in the same group and identified as $\triangle \mathrm{BAP}$. There were no significant differences in serum $\triangle \mathrm{BAP}$ values among the three groups (Figure $\mathbf{1 b}$ ). The serum $\triangle \mathrm{BAP}$ values in the CLP group gradually decreased, but the difference between the CLP group and ETR-P1/fl group did not reach significance (Figure 1b). Serum $\triangle \mathrm{BAP}$ values in the sham group remained at the same levels until $6 \mathrm{~h}$.

\section{OSI:TH/BAP}

The serum OSI values at each time sample were compared with those measured before CLP in the same group and identified as $\triangle$ OSI.

Serum $\triangle$ OSI in the CLP group rapidly increased at $1 \mathrm{~h}$ and remained high at $3 \mathrm{~h}$. Serum $\Delta$ OSI was significantly higher in the CLP group than in the ETR-P1/fl group at $1 \mathrm{~h}$ and $3 \mathrm{~h}$
$(1.32 \pm 0.15$ vs. $0.82 \pm 0.06$ at $1 \mathrm{~h}, 1.35 \pm 0.15$ vs. $0.85 \pm 0.06$ at $3 \mathrm{~h}, P<0.05$ and 0.05 , respectively; Figure $1 \mathrm{c})$.

In the ETR-P1/fl group, serum $\Delta$ OSI remained similar to that in the sham group. Although serum $\Delta$ OSI in the ETR-P1/ fl group tended to be lower than that in the sham group, this difference between the two groups was not significant.

\section{Serum IL-6}

In the CLP group, serum IL-6 levels increased post-CLP and were significantly higher than those in the sham group at 1 and $3 \mathrm{~h}(295 \pm 115 \mathrm{pg} / \mathrm{ml}$ vs. $25.2 \pm 6.89 \mathrm{pg} / \mathrm{ml}$ at $1 \mathrm{~h}, 322 \pm 75.4 \mathrm{pg} /$ $\mathrm{ml}$ vs. $39.5 \pm 9.12 \mathrm{pg} / \mathrm{ml}$ at $3 \mathrm{~h}, P<0.05$ and 0.05 , respectively; Figure 2).

Serum IL-6 levels in the ETR-P1/fl group remained at levels similar to those seen in the sham group and lower than those seen in the CLP group at 1 and $3 \mathrm{~h}(32.3 \pm 23.8 \mathrm{pg} / \mathrm{ml}$ vs. $295 \pm$ $115 \mathrm{pg} / \mathrm{ml}$ at $1 \mathrm{~h}, 108.4 \pm 37.4 \mathrm{pg} / \mathrm{ml}$ vs. $322 \pm 75.4 \mathrm{pg} / \mathrm{ml}$ at $3 \mathrm{~h}$, $P<0.05$ and 0.05, respectively; Figure 2). By 6 h, serum IL-6 levels in the ETR-P1/fl group had increased to a level similar to that seen in the CLP group.

Serum IL-6 levels in the sham group did not increase at any point in the study.

\section{Serum Glutamic Oxaloacetic Transaminase and Creatinine}

Serum glutamic oxaloacetic transaminase (GOT) levels in the ETR-P1/fl group remained essentially similar to those seen in the sham group throughout the study (Table 1). In the CLP group, serum GOT gradually increased to levels higher than those seen in the ETR-P1/fl group at 3 and $6 \mathrm{~h}(44.0 \pm 7.55 \mathrm{IU} / \mathrm{l}$ vs. $23.9 \pm 2.04 \mathrm{IU} / \mathrm{l}$ at $3 \mathrm{~h} ; 50.8 \pm 14.2 \mathrm{IU} / \mathrm{l}$ vs. $20.0 \pm 2.00 \mathrm{IU} / \mathrm{l}$ at $6 \mathrm{~h}, P<0.05$ and 0.05 , respectively).

There were no significant differences among the three groups in their serum creatinine levels at any point in the study (Table 1).

\section{DISCUSSION}

The major finding in this study is that ETR-P1/fl can prevent sepsis-induced elevation of TH, TH/BAP, and the inflammatory a

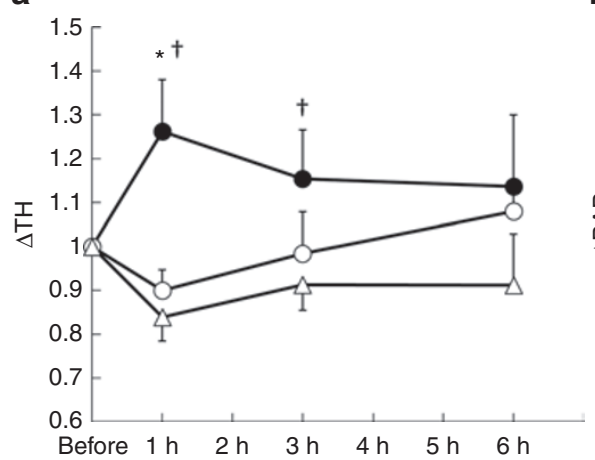

b

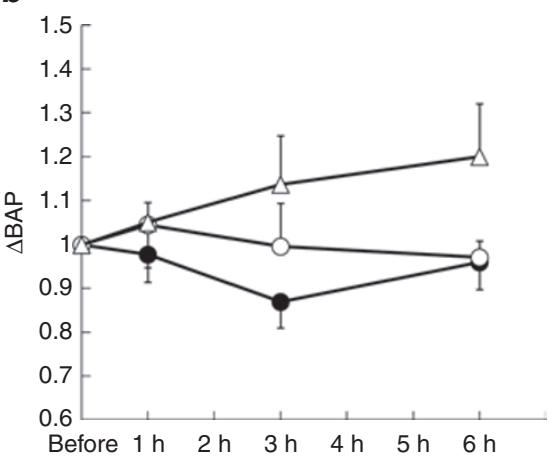

C

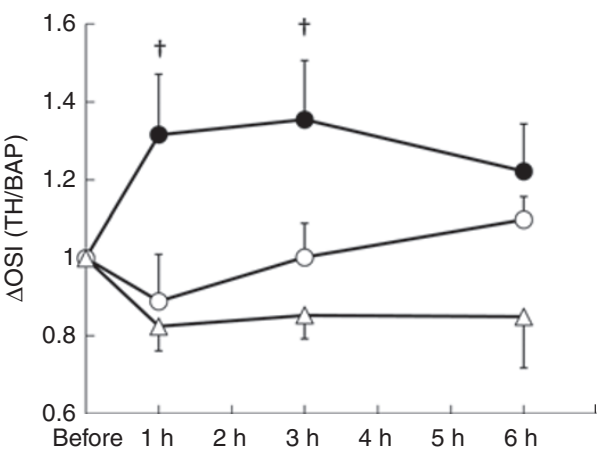

Figure 1. Serial measurement of (a) $\Delta$ total hydroperoxide (TH), (b) $\Delta$ biological antioxidant potentials (BAP), and (c) $\Delta$ oxidative stress index (OSI) (TH/BAP) in the endothelin receptor (ETR)-P1/fl group (open triangles), the cecal ligation and perforation (CLP) group (filled circles), and the sham group (open circles). $\triangle \mathrm{TH}$ was significantly increased in the CLP group, where it was higher than that in the ETR-P1/fl group at 1 and $3 \mathrm{~h}(P<0.05)$. $\triangle \mathrm{BAP}$ in the ETR-p1/fl group increased gradually, and tended to be higher than in the CLP group or the sham group, although this difference was not significant. The $\triangle \mathrm{OSI}$ (TH/BAP) was significantly higher in the CLP group than in the ETR-P1/fl group at $1 \mathrm{~h}$ and $3 \mathrm{~h} .{ }^{*} P<0.05$ as compared with the sham group. ${ }^{\dagger} P<0.05$ as compared with the ETR-P1/fl group. Values are expressed as means \pm SEM. 


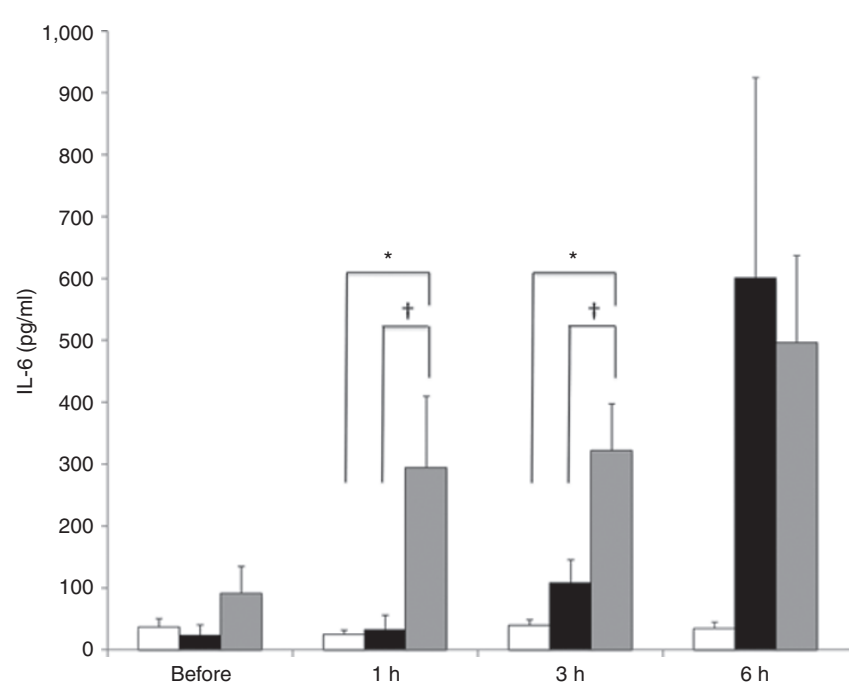

Figure 2. Serial serum levels of interleukin-6 in the sham group (white bar), the cecal ligation and perforation group (gray bar), and the endothelin receptor (ETR)-P1/fl group (black bar). ${ }^{*} P<0.05$ as compared with the sham group. ${ }^{\dagger} P<0.05$ as compared with the ETR-P1/fl group. Values are expressed as means \pm SEM.

Table 1. Serial serum GOT and creatinine levels in the CLP group $(n=6)$, the ETR-P1/fl group $(n=6)$, and the sham $(n=6)$ group

\begin{tabular}{lcccc}
\hline Time & Before CLP & $1 \mathrm{~h}$ & $3 \mathrm{~h}$ & $6 \mathrm{~h}$ \\
\hline GOT (IU/I) & & & & \\
$\quad$ Sham & $39.5 \pm 6.81$ & $36.5 \pm 16.5$ & $32.2 \pm 5.62$ & $32.2 \pm 4.77$ \\
CLP & $42.0 \pm 7.13$ & $47.7 \pm 10.2$ & $44.0 \pm 7.55^{*}$ & $50.8 \pm 14.2^{*}$ \\
$\quad$ ETR-P1/fl & $27.3 \pm 4.09$ & $27.7 \pm 1.99$ & $23.9 \pm 2.04$ & $20.0 \pm 2.00$ \\
\multicolumn{2}{l}{ Creatinine (mmol/l) } & & & \\
$\quad$ Sham & $0.43 \pm 0.025$ & $0.50 \pm 0.10$ & $0.40 \pm 0.03$ & $0.46 \pm 0.07$ \\
CLP & $0.46 \pm 0.025$ & $0.47 \pm 0.03$ & $0.40 \pm 0.03$ & $0.63 \pm 0.09$ \\
ETR-P1/fl & $0.52 \pm 0.025$ & $0.47 \pm 0.02$ & $0.47 \pm 0.01$ & $0.59 \pm 0.04$ \\
\hline
\end{tabular}

Values are expressed as means \pm SEM

CLP, cecal ligation and perforation; ETR, endothelin receptor; GOT, glutamic oxaloacetic transaminase.

${ }^{*} P<0.05$ as compared with the ETR-P1/fl group.

mediator IL-6. In our previous study, a neonatal sepsis model similar to that used here exhibited gradual increases in TH and IL-6 during the experimental course (17). This was associated with elevated levels of cytokines such as tumor necrosis factor- $\alpha$ and highly mobile group-1 box protein produced by monocytes and macrophages $(18,19)$.

Sepsis occurs as a result of complex host-pathogen interactions that lead to the release of inflammatory mediators as well as ROS. ROS are known to take part in physiological reactions and signal transmission. Oxygen free radicals, for example, can serve as the second messengers for the activation of nuclear factor- $\mathrm{\kappa B}(20)$ and the expression of cytokines (21). When ROS synthesis is excessive, however, the effects can be deleterious, often resulting in the development of cardiovascular and pulmonary disorders. During sepsis, excess production of ROS can induce significant cytotoxicity to organs and contribute to the sequence of severe sepsis (22).
This is of great importance in newborns because they have less protection against oxidation (23). Studies have reported oxidative stress in neonatal sepsis (24), and an endothelin mechanism affecting oxidative stress has been implicated in septic shock. The mechanisms underlying these effects of ET-1 release have not been clearly defined, although they could be essential in developing approaches to prevent and treat oxidative stress complicating neonatal sepsis conditions.

The $\mathrm{O}_{2}$ scavenger edaravone has a suppressive effect on the release of cytokines and oxidative mediators and therefore can limit the oxidant-antioxidant imbalance associated with severe systemic inflammation and multiple organ damage in neonatal sepsis (25). This experiment demonstrated that ETR-P1/fl could similarly prevent the sepsis-induced elevation of oxidative stress mechanisms and thus improve the health of the cardiopulmonary system in neonatal sepsis. For example, our study indicated that IL-6, a pleiotropic cytokine with both pro- and anti-inflammatory properties (26), was suppressed in the ETR-P1/fl group at 1 and $3 \mathrm{~h}$. Thus ETR-P1/fl had a similar effect on both IL-6 and TH.

Inflammatory cytokines produced in excessive amounts in response to endotoxins are known to stimulate the production of ET-1 from the endothelium (27). Such an increase in ET-1 levels results in subsequent nicotinamide adenine dinucleotide phosphate oxidase activation and superoxide generation through the action of ET-1 on the ETA receptors (28). Li et al. have demonstrated that ET-1 also increases levels of $\mathrm{O}_{2}^{-}$through the ETA receptors, and that $\mathrm{O}_{2}^{-}$augments ET-1induced vasoconstriction (28). In addition to increasing the production of ROS, ET-1 also augments their expression, a process that can be suppressed by treatment with ETA receptor antagonists but not ETB receptor antagonists (29). These studies show that $\mathrm{O}_{2}^{-}$formation is independent of ETB receptor activation, and that ETA receptors mediate both the $\mathrm{O}_{2}^{-}$formation and the vasoconstriction induced by ET-1 production. A previous study has demonstrated that the reduction of vascular $\mathrm{O}_{2}{ }^{-}$generation ameliorates endothelium-dependent relaxation in deoxycorticosterone acetate salt (30). Our findings in this study also support the role of ET-1 in oxidative stress production through ETA receptors under septic conditions.

A potentially important factor affecting the role of ET-1 in sepsis is its interaction with nitric oxide (NO). NO has received a lot of attention as the major cause of the vascular dysfunction that occurs in sepsis (31). ET-1 stimulates NO synthase to synthesize NO in endothelial cells through the ETB receptor. A previous report has shown that inhibiting $\mathrm{NO}$ generation reduces the vasodilation response to an ETA receptor antagonist by $95 \%$ (32). These findings suggest that the synthesis of NO plays an important role in the vasodilatation induced by ET receptor antagonists. Furthermore, the elevation of ET-1 observed during the inflammatory mechanism in severe sepsis leads to excessive production of $\mathrm{NO}$ and a decrease in circulating antioxidants, which in turn induce oxidative stress status (33). Nevertheless, very little is known about the roles of and the relationship between ROS and NO, particularly with respect to the role of oxidant stress during the early stages of sepsis, 
although NO and NO synthase have recently been proposed as key regulators of the augmentation of tissue injury through the modulation of ROS production (34).

In our sepsis model, we observed an elevation in nitric oxide metabolites levels in the CLP group (19). We have previously reported that ETR-P1/fl inhibits the elevation of nitric oxide metabolites, which may help to maintain mean arterial pressure in the ETR-P1/fl group as compared with that in the CLP group (16). A previous study has similarly indicated that ETR-P1/fl treatment suppresses NO synthesis (35). Furthermore, previous studies have shown that ETR-p1/fl inhibits mast cell degranulation (36), as well as the processes of histamine liberation and secondary granulocyte accumulation through its inhibitory effect on ET-1 (37).

In another recent study, we examined the effect of ETR-P1/fl on immunological responses in H5N1-infected chicks (38). In that study, ETR-P1/fl resulted in a $100 \%$ rescue of the infected chicks. We suspected that ETR-P1/fl attenuated the cytokine storm and oxidative stress injury in the treated chicks. Our current study also supports this hypothesis.

The ETR-P1/fl being a small, 22-amino-acid, peptide fragment of human ETA receptor, with a low molecular weight of $2,491.93 \mathrm{kDa}$, enables it to be administered intravenously; it is characterized by a short serum elimination half-life of $15 \mathrm{~min}$ (data not shown). This in turn facilitates giving the drug in critically ill patients, especially in gut disease involvement as in necrotizing enterocolitis, a major cause of neonatal sepsis, and as in the present septic CLP model. In contrast, bosentan, an oral dual endothelin receptor antagonist, is administered orally only, metabolized in the liver, and excreted in the bile (39).

Our neonatal sepsis model is intended to represent the pathophysiological changes that occur in neonatal sepsis and septic shock and is used to evaluate the mechanisms involved in specific treatments for these conditions. Due to the early observed TH surge at $1 \mathrm{~h}$ post-CLP, experienced by us while using this model, we selected $30 \mathrm{~min}$ post-CLP to be the starting time for treatment (17). Because we used piglets from a local farm instead of commercially available piglets, our animals had been exposed to bacterial antigens in their native environments (40). This primary exposure could have promoted stronger immunological responses to CLP in the newborn piglets used in this study.

In summary, ETR-P1/fl treatment significantly attenuated the elevation of TH, OSI, and IL-6 in a progressive neonatal sepsis CLP model. ETR-P1/fl is worthy of further study regarding its potential use in therapy for neonatal sepsis. To the best of our knowledge, this is the first report that shows the efficacy of ETR-P1/fl treatment in preventing the development of oxidative stress in a neonatal sepsis model. Thus, ETR-P1/fl therapy is worthy of further clinical trials.

\section{METHODS}

\section{Animal Preparation}

Experiments were performed in adherence with the National Institutes of Health guidelines on the use of experimental animals, and the protocol was approved by the ethics committee of Nagoya City University Graduate School of Medical Sciences. Subjects were 18 newborn mixed-strain piglets obtained on their third day of life from a local farmer. The piglets were subsequently divided into three groups: a CLP group $(n=6)$, which received a modified CLP procedure as previously described (19), an ETR-P1/fl group $(n=6)$, which received the same modified CLP procedure but also received ETR-P1/fl treatment $30 \mathrm{~min}$ after CLP, and a sham group $(n=6)$, which received only a sham operation. Piglets were maintained with their mothers and were transported only on the day of their procedures.

Piglets were premedicated with an intramuscular injection of ketamine chloride $(10 \mathrm{mg} / \mathrm{kg})$, and anesthesia was then induced using pentobarbital sodium $(5 \mathrm{mg} / \mathrm{kg} / \mathrm{h})$ in $5 \%$ glucose solution via a peripheral line at a rate of $5 \mathrm{ml} / \mathrm{kg} / \mathrm{h}$ throughout the study to avoid hypovolemia. All surgical procedures were performed under sterile conditions.

Each piglet underwent a tracheotomy and was intubated with an endotracheal tube (internal diameter $3.5 \mathrm{~mm}$ ) and ventilated with an infant ventilator (IV-100; Sechrist Industries, Anaheim, CA). Inspiration/expiration pressures were initially set at $14 / 4 \mathrm{~cm} \mathrm{H}_{2} \mathrm{O}$, with an inspiration time of $0.5 \mathrm{~s}$ using room air. Pressures were then adjusted to maintain $\mathrm{PaCO}_{2}$ at $30-50 \mathrm{~mm} \mathrm{Hg}$ throughout the experiments. A cut-down procedure was used to insert a $4 \mathrm{~F}$ polyvinyl catheter into the left femoral artery for blood sampling.

Modified CLP was performed on piglets in the CLP group and on those in the ETR-P1/fl group. Briefly, a paramedian incision $\sim 4 \mathrm{~cm}$ long was made, sufficient to expose the cecum and terminal ileum. The ileocecal artery was identified and ligated near the cecum, resulting in devascularization of the distal end of the cecum. A $1-\mathrm{cm}$ incision was made on the antimesenteric side. The cecum was gently milked to extrude feces into the peritoneal cavity. The abdominal incision was then closed. In the sham group, the cecum was exposed for $2 \mathrm{~min}$, and then the abdomen was closed in two layers. The study was continued to the time of spontaneous death or for $24 \mathrm{~h}$. Animals surviving to $24 \mathrm{~h}$ were killed with a lethal dose of phenobarbital sodium.

\section{ETR-P1/fl Treatment}

ETR-P1/fl (VLNLCALSVDRYRAVASWRVI; Kurabo, Osaka, Japan) treatment was started $30 \mathrm{~min}$ after the CLP procedure at a rate of $0.05 \mathrm{mg} / \mathrm{kg} / \mathrm{h}$ in $5 \%$ glucose solution via a central venous line; total i.v. fluids were adjusted to maintain a volume of $5 \mathrm{ml} / \mathrm{kg} / \mathrm{h}$ throughout the study.

The detailed design of the antisense peptide has been described previously (13) and was based on the antisense homology-box-derived peptide ETR-p1: NH2-CALSVDRYRAVASW-COOH, which is a fragment of human ETA receptor and may have inhibitory properties. To increase the specific activity of ETR-p1, a simplistic approach was taken of adding flanking amino acids to correct for the change in hydropathic profile to produce ETR-p1/f1: NH2-VLNLCALSVDRYRAVASWSRVI-COOH. The 22 -amino-acid peptide was synthesized by an automated peptide synthesizer followed by high-performance liquid chromatography purification and the final product was freeze dried for storage.

\section{Experimental Protocol}

In each group, blood samples were aseptically collected from the femoral arterial catheter to measure arterial blood gases, serum TH, BAP, IL-6, serum GOT, and creatinine. These samples were taken before the CLP operation and at 1,3 , and $6 \mathrm{~h}$ post-CLP. All samples were placed into pyrogen-free sterilized tubes.

\section{Measurements}

Serum TH was measured with a free radical analytic system using the derivatives of a reactive oxygen metabolites kit (Diacron srl, Grosseto, Italy). Briefly, in the presence of iron (which is released from the proteins by an acidic buffer), free radicals are able to generate alkoxyl and peroxyl radicals according to the Fenton reaction. Such radicals, in turn, are able to oxidize an alkyl-substituted aromatic amine (A-NH2, dissolved in a chromogenic mixture), which transforms them into a pink-colored derivative. Finally, this colored derivative was photometrically quantified. The intensity of the developed color is directly proportional to the concentration of $\mathrm{TH}$.

Serum BAP was measured using a commercial assay kit (Diacron srl). The BAP test is based on the ability of a colored solution, containing a source of ferric $\left(\mathrm{Fe}^{3+}\right)$ ions adequately bound to a special 
chromogenic substrate, to decolor when $\mathrm{Fe}^{3+}$ ions are reduced to ferrous ions $\left(\mathrm{Fe}^{2+}\right)$ upon the addition of a reducing/antioxidant system. In the BAP test, the small amount of blood serum $(10 \mu \mathrm{l})$ to be tested is dissolved in a colored solution that has been obtained by the precise mixing of a source of ferric ions.

Serum IL-6 was measured using immunoassay kits specific for porcine IL-6 (R\&D Systems, Minneapolis, MN). Serum GOT and creatinine were determined with the help of SRL (Tokyo, Japan).

\section{Statistical Analysis}

The distributions of data were tested using the Shapiro-Wilk test. The means of the measurements from all three groups (intergroup means) at particular time points until $9 \mathrm{~h}$ were compared using ANOVA, followed by the Bonferroni post hoc test. If the data were not normally distributed, the Kruskal-Wallis test was used and, when significance was detected, the Mann-Whitney test was used. Data are reported as means \pm SEM. Probability values of $\leq 0.05$ were considered significant. All data analyses were performed with the commercially available statistical analysis software package SPSS (Statistical Package for Social Sciences, Chicago, IL).

\section{STATEMENT OF FINANCIAL SUPPORT}

This study received no financial support from extramural sources.

\section{REFERENCES}

1. Morise Z, Ueda M, Aiura K, Endo M, Kitajima M. Pathophysiologic role of endothelin-1 in renal function in rats with endotoxin shock. Surgery 1994;115:199-204.

2. Figueras-Aloy J, Gómez-Lopez L, Rodríguéz-Miguélez JM, et al. Plasma endothelin-1 and clinical manifestations of neonatal sepsis. J Perinat Med 2004;32:522-6.

3. Rosenberg AA, Kennaugh J, Koppenhafer SL, Loomis M, Chatfield BA, Abman SH. Elevated immunoreactive endothelin-1 levels in newborn infants with persistent pulmonary hypertension. J Pediatr 1993;123:109-14.

4. Yanagisawa M, Kurihara H, Kimura S, et al. A novel potent vasoconstrictor peptide produced by vascular endothelial cells. Nature 1988;332:411-5.

5. Sumner MJ, Cannon TR, Mundin JW, White DG, Watts IS. Endothelin ETA and ETB receptors mediate vascular smooth muscle contraction. Br J Pharmacol 1992;107:858-60.

6. de Nucci G, Thomas R, D'Orleans-Juste P, et al. Pressor effects of circulating endothelin are limited by its removal in the pulmonary circulation and by the release of prostacyclin and endothelium-derived relaxing factor. Proc Natl Acad Sci USA 1988;85:9797-800.

7. Silveira RC, Procianoy RS. Evaluation of interleukin-6, tumour necrosis factor-alpha and interleukin-1beta for early diagnosis of neonatal sepsis. Acta Paediatr 1999;88:647-50.

8. Casey LC, Balk RA, Bone RC. Plasma cytokine and endotoxin levels correlate with survival in patients with the sepsis syndrome. Ann Intern Med 1993;119:771-8.

9. Sullivan JS, Kilpatrick L, Costarino AT Jr, Lee SC, Harris MC. Correlation of plasma cytokine elevations with mortality rate in children with sepsis. J Pediatr 1992;120(4 Pt 1):510-5.

10. Saugstad OD. Mechanisms of tissue injury by oxygen radicals: implications for neonatal disease. Acta Paediatr 1996;85:1-4.

11. Buonocore G, Perrone S, Longini M, Terzuoli L, Bracci R. Total hydroperoxide and advanced oxidation protein products in preterm hypoxic babies. Pediatr Res 2000;47:221-4.

12. Dohi K, Satoh K, Ohtaki H, et al. Elevated plasma levels of bilirubin in patients with neurotrauma reflect its pathophysiological role in free radical scavenging. In Vivo 2005;19:855-60.

13. Baranyi L, Campbell W, Ohshima K, Fujimoto S, Boros M, Okada H. The antisense homology box: a new motif within proteins that encodes biologically active peptides. Nat Med 1995;1:894-901.

14. Baranyi L, Campbell W, Ohshima K, et al. Antisense homology box-derived peptides represent a new class of endothelin receptor inhibitors. Peptides 1998;19:211-23.

15. Szalay L, Kaszaki J, Nagy S, Boros M. The role of endothelin-1 in circulatory changes during hypodynamic sepsis in the rat. Shock 1998;10:123-8.
16. Goto T, Hussein MH, Kato S, et al. Endothelin receptor antagonist attenuates inflammatory response and prolongs the survival time in a neonatal sepsis model. Intensive Care Med 2010;36:2132-9.

17. Kakita H, Hussein MH, Daoud GA, et al. Total hydroperoxide and biological antioxidant potentials in a neonatal sepsis model. Pediatr Res 2006;60:675-9.

18. Hussein $M H$, Kato $T$, Sugiura $T$, et al. Effect of hemoperfusion using polymyxin B-immobilized fiber on IL-6, HMGB-1, and IFN gamma in a neonatal sepsis model. Pediatr Res 2005;58:309-14.

19. Kato T, Hussein MH, Sugiura T, et al. Development and characterization of a novel porcine model of neonatal sepsis. Shock 2004;21:329-35.

20. Schreck R, Rieber P, Baeuerle PA. Reactive oxygen intermediates as apparently widely used messengers in the activation of the NF-kappa B transcription factor and HIV-1. EMBO J 1991;10:2247-58.

21. Satriano JA, Shuldiner M, Hora K, Xing Y, Shan Z, Schlondorff D. Oxygen radicals as second messengers for expression of the monocyte chemoattractant protein, JE/MCP-1, and the monocyte colony-stimulating factor, CSF-1, in response to tumor necrosis factor-alpha and immunoglobulin G. Evidence for involvement of reduced nicotinamide adenine dinucleotide phosphate (NADPH)-dependent oxidase. J Clin Invest 1993;92:1564-71.

22. Fialkow L, Wang Y, Downey GP. Reactive oxygen and nitrogen species as signaling molecules regulating neutrophil function. Free Radic Biol Med 2007;42:153-64.

23. Hara K, Yamashita S, Fujisawa A, Ishiwa S, Ogawa T, Yamamoto Y. Oxidative stress in newborn infants with and without asphyxia as measured by plasma antioxidants and free fatty acids. Biochem Biophys Res Commun 1999;257:244-8

24. Cancelier AC, Petronilho F, Reinke A, et al. Inflammatory and oxidative parameters in cord blood as diagnostic of early-onset neonatal sepsis: a case-control study. Pediatr Crit Care Med 2009;10:467-71.

25. Kato S, Hussein MH, Kakita H, et al. Edaravone, a novel free radical scavenger, reduces high-mobility group box 1 and prolongs survival in a neonatal sepsis model. Shock 2009;32:586-92.

26. Tilg H, Trehu E, Atkins MB, Dinarello CA, Mier JW. Interleukin-6 (IL-6) as an anti-inflammatory cytokine: induction of circulating IL-1 receptor antagonist and soluble tumor necrosis factor receptor p55. Blood 1994;83:113-8.

27. Huribal M, Kumar R, Cunningham ME, Sumpio BE, McMillen MA. Endothelin-stimulated monocyte supernatants enhance neutrophil superoxide production. Shock 1994;1:184-7.

28. Li L, Watts SW, Banes AK, Galligan JJ, Fink GD, Chen AF. NADPH oxidase-derived superoxide augments endothelin-1-induced venoconstriction in mineralocorticoid hypertension. Hypertension 2003;42:316-21.

29. Callera GE, Touyz RM, Teixeira SA, et al. ETA receptor blockade decreases vascular superoxide generation in DOCA-salt hypertension. Hypertension 2003;42:811-7.

30. Somers MJ, Mavromatis K, Galis ZS, Harrison DG. Vascular superoxide production and vasomotor function in hypertension induced by deoxycorticosterone acetate-salt. Circulation 2000;101:1722-8.

31. Landry DW, Oliver JA. The pathogenesis of vasodilatory shock. N Engl J Med 2001;345:588-95.

32. Verhaar MC, Strachan FE, Newby DE, et al. Endothelin-A receptor antagonist-mediated vasodilatation is attenuated by inhibition of nitric oxide synthesis and by endothelin-B receptor blockade. Circulation 1998;97:752-6.

33. Skalska AB, Pietrzycka A, Stepniewski M. Correlation of endothelin 1 plasma levels with plasma antioxidant capacity in elderly patients treated for hypertension. Clin Biochem 2009;42:358-64.

34. Handa O, Stephen J, Cepinskas G. Role of endothelial nitric oxide synthase-derived nitric oxide in activation and dysfunction of cerebrovascular endothelial cells during early onsets of sepsis. Am J Physiol Heart Circ Physiol 2008;295:H1712-9.

35. Eszlári E, Czóbel M, Molnár G, et al. Modulation of cardiac contractility through endothelin-1 release and myocardial mast cell degranulation. Acta Physiol Hung 2008;95:267-85.

36. Boros M, Szalay L, Kaszaki J. Endothelin-1 induces mucosal mast cell degranulation and tissue injury via ETA receptors. Clin Sci 2002;103:Suppl 48:31S-4S. 
37. Kaszaki J, Czóbel M, Szalay L, Nagy S, Boros M. Endothelin-1 induces organ-specific histamine liberation and neutrophil granulocyte accumulation in the rat. Inflamm Res 2008;57:396-402.

38. Imai MM, Okada AA, Okada $\mathrm{HH}$, et al. Rescue with an anti-inflammatory peptide of chickens infected H5N1 avian flu. Nature Precedings 2009. (http://hdl.handle.net/10101/npre.2009.3425.1.)
39. Beghetti M, Haworth SG, Bonnet D, et al. Pharmacokinetic and clinical profile of a novel formulation of bosentan in children with pulmonary arterial hypertension: the FUTURE-1 study. Br J Clin Pharmacol 2009;68:948-55.

40. O'Brien WF, Golden SM, Davis SE, Bibro MC. Endotoxemia in the neonatal lamb. Am J Obstet Gynecol 1985;151:671-4. 